\title{
Moving beyond the nature-based solutions discourse: introducing nature-based thinking
}

\author{
Thomas B. Randrup ${ }^{1} \cdot$ Arjen Buijs $^{2}$ - Cecil C. Konijnendijk ${ }^{3} \cdot$ Tom Wild $^{4}$ \\ Published online: 3 March 2020 \\ (C) The Author(s) 2020
}

\begin{abstract}
Suites of concepts and approaches have been launched during recent years to promote urban nature and greener cities. However, it is doubtable whether tinkering within the current economic and political system can provide adequate solutions. Nature-based Solutions can be seen as a new conceptual approach to the human-ecological connection, and as an outcome of an evolutionary development of socio-ecological concepts. In this Communication, we argue for drawing up inspiration by nature as an outset for the development of more sustainable and inclusive cities, balancing anthropocentric and ecocentric values and acknowledging the importance of the social and governance dimensions in a more balanced socio-ecological perspective. We call this approach Nature-based Thinking.
\end{abstract}

Keywords Nature-based solutions · Nature-based thinking · Governance · Management, urban open spaces

\section{Introduction}

Urbanisation, as a continuous, gradual and sometimes dramatic shift in human habitat from rural to urban, is a global megatrend (unpopulation.org 2018). Being a major anthropogenic driver of environmental change, degradation and loss of biodiversity, urbanisation is set to increase by 1 million $\mathrm{km}^{2}$ by 2030 . With humans gathering in urban centres, ironically

\section{Highlights}

- Suites of concepts have been launched to promote urban nature and greener cities.

- Contemporary international agreements suggest that more transformative changes are needed.

- The new concept of Nature-based Thinking (NBT) is introduced.

- NBT is a rethinking of the traditional linear logic of planning, design, construction, and maintenance, seen as a holistic cycle in which nature prevail, and come to dominate.

- NBT builds on the three dimensions of ecology, community participation aspects, and the governance context, as well as the interlinkages between the three dimensions.

Thomas B. Randrup

thomas.randrup@slu.se

Arjen Buijs

arjen.buijs@wur.nl

Cecil C. Konijnendijk

cecil.konijnendijk@ubc.ca

Tom Wild

t.wild@sheffield.ac.uk human health and well-being are affected negatively in many respects; urbanization and poverty have gone hand in hand for decades, with the population living under the level of poverty in urban areas having increased with 50 million during 19932002 (Ravallion et al. 2007; Andersson et al. 2015; Dobbs et al. 2017). However, urbanisation and the ongoing transformation of existing urban areas can be seen as being both the cause of the environmental and social degradation, as well as a
1 Swedish University of Agricultural Sciences, PO Box 58, 23 053 Alnarp, Sweden

2 Wageningen University \& Research, PO Box 47, 6700AA Wageningen, The Netherlands

3 University of British Columbia, 2045-2424 Main Mall, Vancouver, BC V6T 1Z4, Canada

4 University of Sheffield, Firth Court, Sheffield S10 2TN, England 
potential solution to the problems it causes (Capon 2017). By 2030 , the urban population in the world's less-developed regions will total 4 billion, of which $80 \%$ will live in Africa, Asia and Latin America (FAO 2017).

As parts of a wider agenda, suites of concepts and approaches have been launched during recent years to promote urban nature and greener cities. These include e.g. sustainable urban development (World Commission on Environment and Development 1987), sustainable urban design (European Commission 2004), (urban) ecosystem services provision (TEEB 2010; Bolund and Hunhammer 1999), green infrastructure development (Benedict and McMahon 2006; European Commission 2013), and ecosystem-based adaptation (Colls et al. 2009). Most recently, nature-based solutions (NBS) (European Commission 2015), the Intergovernmental Science-Policy Platform on Biodiversity and Ecosystem Services' (IPBES) note on Nature's Contribution to People (Escobedo et al. 2018), and the United Nations' 17 Sustainable Development Goals may be seen as efforts to address humans' dependency upon nature, in restoring and developing not only urban areas, but human life in general. These concepts and approaches are all examples of an increased attention towards the importance of nature and ecosystems in an urbanizing world.

The NBS concept can be defined as "solutions that are inspired and supported by nature, which are cost-effective, simultaneously provide environmental, social and economic benefits and help build resilience. Such solutions bring more, and more diverse, nature and natural features and processes into cities, landscapes and seascapes, through locally adapted, resource-efficient and systemic interventions." (EC 2015). It builds on these previous concepts, and emphasises the need for local action or finding solutions for major societal challenges. Meanwhile, the increased emphasis on economic and instrumental values as well as technocratic solutions has not hindered the rapid decline of natural areas and biodiversity (IPBES 2019); in the light of the Intergovernmental Panel on Climate Change's recommendations for a significant reduction of $\mathrm{CO}_{2}$ before 2030, it is debatable whether the current focus on using and valuing nature is the right approach (IPCC 2019).

Both the Paris Agreement on climate change as well as the recent IPBES report (IPBES 2019) suggest that a more transformative change is needed. As stated explicitly in the IPBES report, current trajectories and implementation of policy responses are insufficient to halt biodiversity degradation to the extent deemed necessary. Furthermore, biodiversity decline hinders policy efforts towards the Sustainable Development Goals, including SDG-11 on Sustainable Cities and Communities. Key-message $\mathrm{C}$ of the IPBES report explicitly argues that "Goals for conserving and sustainably using nature and achieving sustainability cannot be met by current trajectories, and goals for 2030 and beyond may only be achieved through transformative changes across econom$i c$, social, political and technological factors" (IPBES 2019, p. 6). Developing and implementing NBS is helpful to counter local environmental, social and, economic issues. However, we argue that the changes aimed for by IPBES and others needs to be translated into more transformative languages and concepts.

In this communication, we argue that the NBS notion of "being inspired by nature" needs to be reconsidered in the light of this instrumental and technological perspective.

We suggest that recent thinking to reconnect humans and nature (or "non-human nature"), as well as acknowledging human-nature-technology relationships may offer new and more integrated pathways towards urban sustainability. For this, we revisit the adage of being inspired by nature, and argue that acknowledging the interconnectedness of humans, nature and technology is a useful starting point to be inspired by natural processes in all aspects of urban development to create more holistic approaches to sustainable cities. By balancing anthropocentric and ecocentric values, as well as the relational values of nature, in combination with acknowledging the importance of the social and governance dimensions in a more balanced socio-ecological perspective, more healthy and long-term sustainable urban nature solutions may be developed. Because the naming and framing of our quest is relevant for the solutions we develop (Lakoff and Johnson 2003), we suggest to broaden the concept and definition of NBS and develop a new Nature-based Thinking (NBT) to contribute to the requested transition towards sustainable cities.

\section{Contemporary concepts are human-centred}

The development of NBS as a new conceptual approach to human-ecological connections may be seen as the present outcome of an evolutionary development of concepts. Although this paper discusses contemporary thinking on sustainable cities, we should not overlook the crucial work by René Descartes, promoting what later became named the Cartesian method, and introducing the dualisms of not only body and mind, but also of nature and culture. This dualism has been dominant ever since, and remained the cornerstone of our thinking when the concept of sustainability was developed in the 1980's (Pereira and Funtowicz 2015). While the sustainability approach continued to distinguish nature, people, and economy, it was innovative in the way that it aimed to weigh nature's needs equally with human social and economic needs. In addition the ecosystem service (ESS) concept was a way of describing and organising the benefits that people derive from nature ('nature's gift to us'). The above concepts and approaches tend to deal with, and relate to finding ways to handle the urbanisation challenges by using and 'mobilising' nature. The development of these concepts shows a clear 
pattern: the naming and framing of our relationship with nature as well as the proposed solutions increasingly focused on instrumental values of nature: what good can it do for me and to us? The introduction of the concept of sustainable development was revolutionary in the sense that it argued that sustainability and (economic) development are intrinsically related to each other. This may be seen as the start of a process of instrumentalisation, and eventually technocratisation of the framing of sustainability issues. Although the IPBES concept of "Nature's Contribution to People" (Díaz et al. 2018) moves away from technocratic interpretations of the value of nature, the focus remains on instrumental values. Recently, the concepts of ESS, Natural Capital and Nature's Contribution to People (ibid) have been critiqued for their technocratic ideals about knowledge, standardization, and science-society relations, for the way they combine nature and techniques, as well as for their quantification of these values (e.g., Turnhout et al. 2013; Schröter et al. 2014; Bekessy et al. 2018).

Several scholars, predominantly from philosophy and anthropology, have argued for the relevance of non-Western approaches to nature to build new connections and responsibilities, (e.g. Latour 1993, Descola 2013). It is argued that to counter current instrumentalisation of nature, science and policy need to overcome these dualities, to build 'hybrids' (Driessen 2017), and as a result several more integrative approaches have been suggested, including "more-than-human" approaches (Whatmore 2002, 2006) and the "more-than-human" city (Franklin 2017), "post-humanist" approaches, "biocultural diversity" (Elands et al. 2015), and "relational values" (Chan et al. 2016). Such emerging efforts to overcome instrumentalisation of nature through a fundamental reconnection of humans and nature can also inspire the development of nature-based thinking.

Indeed, the concept of NBS has important merits, as demonstrated by e.g. increasing attention, projects, policies, and funding (see e.g. Faivre et al. 2017, Frantzeskaki et al. 2017; Pauleit et al. 2017; Escobedo et al. 2018; Frantzeskaki 2019). According to these studies and theoretical reflections, NBS can be critiqued, as it does not necessarily involve nature but in some cases rather focus on technological imitations of nature (such as biomimicry, or hard-engineered stormwater storage structures). The dominance of keywords such as 'solutions' and 'services' in NBS discourse and practices has a strong performative effect on our thinking (see e.g., Ernston and Sörlin 2013): language and knowledge create the realities that they describe (Butler 1997). As such, speaking of solutions or services will focus our (scientific) quest and may explicitly or implicitly downplay attention for nature's contributions or processes that are not seen as a solution or a service. Many projects start from seeking solutions for expert-driven problem definitions, which sets the boundaries for efforts to include -or not- community participation or the relevance intrinsic values of nature in planning, design, construction and management processes. However, a focus on (naturebased) services or solutions is only one part of the bigger picture. We need to look at the relations between cities and nature in a more cyclical way, deriving inspiration from nature with its cyclical and long-term ecological processes. Consequently, it is far from certain and not clear whether existing approaches will really break disciplinary boundaries or drive cross-sectoral integration in transformative ways.

\section{Broadening the scope: nature-based thinking}

In order for planners, designers, managers, and citizens to really embrace nature, we argue that a more transformative 'turn' needs to be made beyond anthropocentric and solutions-based approaches. NBS (technological, scalable nature inspired solutions), GI (plans we make), ESS (systematic of values for humans benefit) etc. need to be placed in a broader framework, a new comprehensive paradigm on how we develop, design, and manage our cities. As a contribution to this quest for transformative change towards sustainable cities, we introduce the concept of Nature-based Thinking. We argue that refocusing our thoughts and speech from Nature-based Solutions to Nature-based Thinking may stimulate a broader nature-based, but also social-ecological (inclusive) approach for greening our cities.

Indeed, Albert et al. (2019) point towards NBS giving back to nature, but framed in terms of the benefits and services that can be extracted. From a transitions perspective, Frantzeskaki et al. (2017) refer to the importance of local initiatives and urban living labs in piloting new ways of thinking and doing, but stop short of defining what is actually meant by 'naturebased thinking and doing'. NBT could be considered as embodying a broader mindset that works in a cyclical way across sectors, disciplines, and levels of governance to make space for nature - including in the densest of urban areas. It focuses not only on implementing NBS over conventional infrastructure with desired and set outcomes in mind, but also allows for less predictable benefits and experiments to discover them through a longer-term perspective.

NBT could be inclusive in two ways: 1) in acknowledging the value of nature beyond solutions and services (recognising nature's intrinsic value; 'nature for nature's sake'), while at the same time 2) being inclusive of culturally diverse and community-centred ways of thinking about and relating to nature. We define NBT as an approach to urban inclusive planning, being inspired by nature to act socially, environmentally as well as economically in the transition towards sustainable cities. A new NBT framework will apply a holistic, nature-based approach to planning, design, construction, management and stewardship of urban nature.

NBT does not only look at nature as providing solutions to urban challenges, it also recognises that more room needs to 
be given over to wilder nature. NBT takes a cyclical approach in creating room for 'wildscapes', and less manicured urban green spaces, but also aims to be truly transdisciplinary. In doings so, NBT should link up with other approaches that place more value on nature itself, such as that of Biophilic Cities (https://www.biophiliccities.org), which is a partnership between cities, scholars and global stakeholders working for an understanding of the value and contribution of nature in cities to the lives of urban residents.

Being socially inclusive also relates to the actors contributing to NBT. Over the last years, many local communities, grassroots initiatives, friends groups and social enterprises have contributed to more sustainable cities (Frantzeskaki et al. 2016; Buijs et al. 2019;). Indeed, while top-down efforts to implement sustainability actions have not always proven successful, growing attention has focused on the transformative potential of non-state actors, including social enterprises and active citizens (Hajer et al. 2015). However, to break boundaries, the epistemological framework at the foundation of our thinking needs to move beyond technical and anthropocentric solutions. At this fundamental level, there is a need to focus on the interactions between people and nature, especially at the individual and community level. Therefore, the aim of NBT to be socially inclusive goes beyond participatory processes to include local residents in decision-making processes. Based on the concept of leverage points (Meadows 1999), we argue that in order to contribute to transformative change, NBT must also reconnect urban populations with nature directly, physically as well as spiritual, emotional etc.

Urbanisation is an important driver for what has been called "the extinction of experience" with nature (Soga and Gaston 2016) and the subsequent loss of public support for sustainability actions (Nisbet et al. 2009). NBT aims to counter this negative feedback loop through reconnecting people with the natural world, by expanding the opportunities for urban populations to experience the unpredictability and heterogeneity of nature. Such experiences are crucial for the philosophical and emotional connections to nature that are considered the deepest leverage points for initiating systemic change towards sustainable cities (Abson et al. 2017; Ives et al. 2018). Expanding the focus from nature-based solutions to deeper conceptualisations of nature will shift the focus from more shallow to deeper leverage points. Indeed it has been shown that ethical consideration related to the noninstrumental or intrinsic value of nature are stronger drivers for change than instrumental values (Runhaar et al. 2019), which we argue are at the core of NBS.

\section{Nature-based thinking in practice}

NBT capitalizes on the potential of cyclical process to plan, design, construct, and manage urban green spaces. Such iterative and evolutionary perspectives in planning have variously been argued for - e.g. in the deliberative planning, delivery and management of urban green infrastructure (GI) (e.g., Forester 1999; Wild et al. 2015), or in the logic, in which planning, design, construction, and maintenance define how NBS are (co)-developed (Jansson et al. 2018). However, the evolution of NBS is perhaps only one step in a transition towards deeper NBT which may require a turn away from traditional landscape planning processes, towards more gradual yet progressive and long-term approaches to restore the benefits and services of urban nature.

NBT acknowledges the time dimension, by balancing strategic and visionary approaches with incremental planning processes. A technical approach to NBS may fall short of understanding the long-term context and interdependencies at the unpredictable and changing environmental, social and governance dimensions. Consequently, in line with the slowtimescale of nature, place-keeping is an essential ingredient, alongside place-making through NBS (Wild et al. 2008; Dempsey and Burton 2012).

To some, implementing NBT in practice may be seen as a redevelopment of the three dimensions defining the sustainability concept. However, a truly holistic practice is added to this, in which the focus shifts to the interlinkages between the ecological, social (and cultural), and economic dimensions. We call for a new, cross-cutting, and interdisciplinary approach to planning, design, construction, and long-term maintenance of urban nature. We suggest that design, construction, and maintenance should be aligned, driven by a design-andmanagement vision that encompasses more than a definitive layout. A long-term construction phase will gradually flow into a long-term establishment phase, which will ultimately flow into an indefinite growth phase. The responsible parties (planners, designers, constructors, maintenance crews, as well as local communities) will work together toward the achievement of the vision, and in doing so allow nature to prevail. Social, ecological and economic conditions are bound to change during this time, and new conditions will arise, allowing for adjustments that may further enhance the opportunities for, and from, urban nature.

\section{Three NBT dimensions}

Overall, we suggest NBT as inspiration for rethinking the traditional linear logic of planning, design, construction, and maintenance. The conventional and often economicallydriven logic of dividing expertise and resources in this way might rather be rethought as a cycle, in which nature can prevail, and increasingly come to the fore. As within the sustainability concept, NBT builds on the three dimensions of ecology, community aspects, and economy, here described as a governance context (see Fig. 1). 


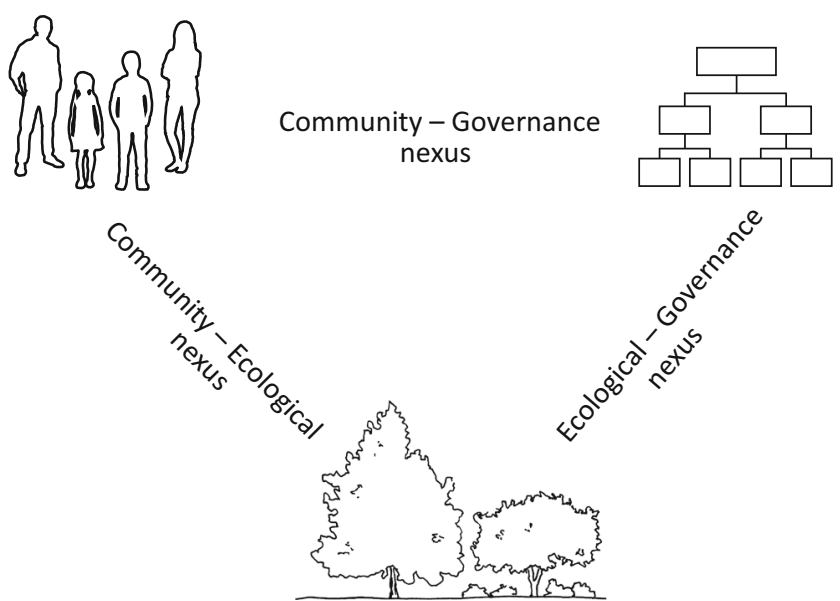

Fig. 1 The three interrelations in NBT. Redeveloped from Jansson et al. (2018)

We suggest the following three dimensions of NBT:

1. By revisiting the ecological dimension we can create more room for nature also beyond human services and solutions, and especially in the urban areas, to build in more space for natural processes, ecosystem functioning, and long term unpredictability.

2. By revisiting the community dimension we can create a new urban aesthetic, in which experiences with a diversity of natural elements may allow for more diversity in what nature (should) look like, rather than the opposite (because of limiting growing conditions, or limitations set by the economic system), and

3. By revisiting the economic dimension and closely-linked political and organizational perspectives of nature in cities, including new governance structures, we may recognize the need to break siloes and build opportunities associated with linking formal government with local communities.

For a truly holistic approach, we not only need to look at the three dimensions, but also at the interlinkages between them. A new NBT paradigm may seek new approaches from including these interlinkages between ecology, economy and the community aspects.

\section{The ecological-governance nexus}

Making room for urban nature is not just about transforming other land uses (e.g. industry, infrastructure, brown fields etc.) to green spaces, for example by making more room for trees along streets. The way new urban developments have often resulted in hostile growing conditions for urban nature will need to change. Growing conditions are defined by planning approaches, design and management concepts and technologies, as well as by governance structures.
Planning has often taken a limiting perspective of nature being merely the 'icing on the cake', introducing green elements as a remedy or means for alleviating hostile urban living conditions for humans. Wind turbulence and excessive heat can be moderated by vegetation, but the basic perspective is that nature is being used to alleviate planning mistakes. Design and management concepts have since the early urban planning ideals dealt with systematic planting alongside streets and other transport corridors. Here, trees grow in rows of the same species or cultivars, often in hostile and limited growing conditions with an estimated street tree population half-life ranging from just 13-20 years (Roman and Scatena 2011). New, often technological solutions (NBS) are developed to optimise ecosystem services, e.g. green roofs (e.g., Eksi et al. 2017), green walls (e.g., Baran and Gültekin 2018) and structural soils for increased street tree survival (e.g. Grabosky et al. 2009). Thus, urban nature suffers from planning which does not leave room for nature, design and construction processes which focus on economy and technical solutions, and maintenance costs which are often neglected (Dempsey and Burton 2012); the prevailing paradigm still concerns 'controlled' nature, based on technological solutions.

Trees need room to grow. We propose that in NBT, urban vegetation including street trees are established in a nature inspired manner, e.g. locating trees strategically where there is room for growth, instead of systematically where technical solutions are needed. This will create natural conditions and require a minimum of maintenance. In practice, this depends upon a nuanced combination of planning and design, construction and maintenance. Deciding that urban nature needs room to grow is basically a political decision, as there is limited room for nature in urban areas with their usually high demand on space. Thus, ecology becomes a frame and a basis for decision making in relation to e.g. resilience in order to prioritise sufficient room for urban nature, and to allow more resource efficient, naturalistic and non-technological growing conditions.

\section{The community-ecological nexus}

In developing and creating room for nature, natural growing conditions are emphasised, and green spaces become wilderi.e. more biodiverse and ecologically complex. We see this already in wildlife gardens, people's interests in e.g., urban gardening, and in the wave of 'urban nature parks', and London being recently declared a 'National Park City' (London.gov 2019). New ecological approaches to e.g. urban water cycles, exemplified by the Sponge City approach in China (e.g. Chan et al. 2018), and management of storm water in American cities by the use of GI may also be examples of this new approach. Such community-ecological approaches have the potential to strengthen and benefit from the 
recognition that humans are part of nature rather than being separated from it. Furthermore they may create new urban aesthetics (Gobster et al. 2007), and thus NBT challenges our traditional conceptualisation of wilderness. In general, cultural diversity in people's preferences for natural areas is underdeveloped (Kloek et al. 2017), but Kowarik (2013, 2018) described the need for diversity of ecological and aesthetic characteristics of urban nature, ranging from pristine wilderness to spontaneously emerged wilderness. Such studies show that biodiverse urban nature tends to be aesthetically pleasing in a broader sense than 'cultured' managed nature (Fischer et al. 2018). While the NBT approach will inherently provide a more naturalistic and wilderness aesthetic in urban areas, it will also bring urban citizens closer to nature with all the related benefits associated to it in terms of human health and well-being (Kaplan 1995; Maas et al. 2009). In relation to feelings of insecurity, it is important that also areas including urban nature are seen as areas under stewardship, and felt by citizens to be cared-for, rather than just abandoned brownfields (Nassauer 2011).

\section{The community-governance nexus}

Human organisations tends to originate from simple structures. Simple organisations have all responsibilities and tasks placed with one or very few individuals, maybe with some tasks being solved externally. As the amount of tasks grows, the organisation grows with a further division of tasks, and an increased need for coordination. Urban areas, managed by local government organisations, are no different to this. During hundreds of years these organisations have expanded, as new tasks, responsibilities, and challenges have been added. These include public services with economic, social, cultural, and technical dimensions. Currently, as urban nature planning and management is often considered a primarily technical service, the responsibilities for urban nature are organised in departments placed remotely from those being responsible for their upkeep, for bearing the cost or indeed, those enjoying the benefits. As a result, organisational silos prevail. The traditional way modern society is organising itself could be inspired by nature, as nature acts across administrative borders; water flows and roots grow irrespective of land ownership or authority.

While governments and large enterprises tend to professionalise into separate silos, communities tend to cherish diversity in urban nature (Frantzeskaki et al. 2016), and an alternative organisational structure is provided by local communities and their organisations (Buijs et al. 2016). Active citizens tend to not only be motivated by environmental concerns, but also by a drive to improve the social fabric, improve the economic structure or bridge cultural divides (Mattijssen et al. 2018). As such, many grassroots and active citizens have an inherent drive towards a more integrated approach to tackle urban issues. Their embeddedness in the local community forces them to recognise the complexity of urban issues and the interconnectedness of environmental and social issues, including issues of social equity and justice. Consequently, they may be more naturally inclined to look beyond simple solutions but start from a more comprehensive and holistic perspective. Developing new modes of governance, such as mosaic governance (Buijs et al. 2016), meta-governance (Sørensen and Torfing 2009) and more incremental planning approaches (Favoreu et al. 2015) is needed to cherish, facilitate or stimulate such community based contributions.

\section{Perspective}

Recognising that humans are an indivisible part of nature, the current Anthropocene also implies a responsibility towards the re-generation of nature, especially in cities. Therefore, the time has come for humans to give back to nature - to create a positive feedback loop - from humans to nature. We suggest that future urban planning be truly inspired by nature in an inclusive and holistic approach to plan and create sustainable cities which can accommodate the increasing urban population. In doing so, we need to balance anthropocentric and ecological values and acknowledge the importance of the social and governance dimensions in a more balanced community-ecological perspective.

There is a need to re-think the way we define concepts from a primarily anthropogenic perspective, and learn from the failure of contemporary governmental/technical approaches; we see the potential to learn and benefit from grassroots efforts to move beyond approaches that only address part of the larger need to fundamentally change our ways of shaping cities. We need to learn from current examples and practices, and to continuously involve a wide range of disciplines, professions, and communities.

We suggest a transition from perspectives and concepts which primarily recognise the performance of nature and the need to showcase via experimentation. Such a transition will gradually lead to changes in policies, regulations, social culture, market mechanisms, and in the end to the human-nature relationship in general. As there is bound to be resistance from existing institutions (and associated experts, planners, managers, and governments), the NBT approach has to be longsighted, while also embracing the need for changes within the educational systems. This transition includes a more holistic perspective of our efforts towards more green and sustainable cities. The NBT perspective not only includes the environmental, social and economic dimensions of sustainability, but has an explicit focus on integrating these dimensions into three interconnected nexi; the ecological-governance nexus, where ecology becomes an integrative part of decision making, the ecological-community nexus, allowing for new urban 
aesthetics beyond manicured and sterile grasslands, and the community-governance nexus, recognising the agency and innovative potential of local communities and businesses. NBT requires that all three dimensions, as well as their interlinkages, are included in decision making. The concept of Nature-based Thinking embodies the perspective of nature with people, rather than just nature for people.

Funding Information Open access funding provided by Swedish University of Agricultural Sciences.

Open Access This article is licensed under a Creative Commons Attribution 4.0 International License, which permits use, sharing, adaptation, distribution and reproduction in any medium or format, as long as you give appropriate credit to the original author(s) and the source, provide a link to the Creative Commons licence, and indicate if changes were made. The images or other third party material in this article are included in the article's Creative Commons licence, unless indicated otherwise in a credit line to the material. If material is not included in the article's Creative Commons licence and your intended use is not permitted by statutory regulation or exceeds the permitted use, you will need to obtain permission directly from the copyright holder. To view a copy of this licence, visit http://creativecommons.org/licenses/by/4.0/.

\section{References}

Abson DJ, Fischer J, Leventon J et al (2017) Leverage points for sustainability transformation. Ambio 46:30-39

Albert C, Schröter B, Haase D, Brillinger M, Henze J, Herrmann S, Gottwald S, Guerrero P, Nicolas C, Matzdorf B (2019) Addressing societal challenges through nature-based solutions: how can landscape planning and governance research contribute? Landsc Urban Plan. https://doi.org/10.1016/j.landurbplan.2018.10.003

Andersson E, Elmqvist T, Kremer P, McPhearson T (2015) Advancing the frontier of urban ecosystem services research: lessons and future challenges. Ecosyst Serv 12(Special issue)

Baran Y, Gültekin AB (2018) Green Wall systems: a literature review. In: Firat S, Kinuthia J, Abu-Tair A (eds) Proceedings of 3rd international sustainable buildings symposium (ISBS 2017). ISBS 2017. Lecture notes in civil engineering, vol 7. Springer

Bekessy SA, Runge MC, Kusmanoff AM, Keith DA, Wintle BA (2018) Ask not what nature can do for you: a critique of ecosystem services as a communication strategy. Biol Conserv 224:71-74

Benedict MA, McMahon ET (2006) Green infrastructure: linking landscapes and communities. Island Press, Washington, D.C.

Bolund P, Hunhammer S (1999) Ecosystem Services in Urban Areas. Ecol Econ 29:293-301

Buijs AE, Mattijssen TJ, Van der Jagt AP et al (2016) Active citizenship for urban green infrastructure: fostering the diversity and dynamics of citizen contributions through mosaic governance. Curr Opin Environ Sustain 22:1-6

Buijs A, Hansen R, Jagt SVD et al (2019) Mosaic governance for urban green infrastructure: Upscaling active citizenship from a local government perspective. Urban For Urban Green 40(2019):53-62

Butler J (1997) Excitable speech: a politics of the Performative. Routledge, New York

Capon A (2017) Harnessing urbanisation for human wellbeing \& planetary health. Lancet Planet Health 1(1):6-7

Chan KMA, Balvanera P, Benessaiah K, Chapman M, Díaz S, GómezBaggethun E, Gould R, Hannahs N, Jax K, Klain S, Luck GW,
Martín-López B, Muraca B, Norton B, Ott K, Pascual U, Satterfield T, Tadaki M, Taggart J, Turner N (2016) Why protect nature? Rethinking values and the environment. Proc Natl Acad Sci U S A 113(6):1462-1465

Chan FKS, Griffiths JA, Higgitt D, Xu S, Zhu F, Tang Y-T, Xu Y, Thorne CR (2018) "Sponge City" in China - a breakthrough of planning and flood risk management in the urban context. Land Use Policy 76:772-778

Colls A, Ash N, Nyman NI (2009) Ecosystem-based adaptation: a natural response to climate change. IUCN commission on ecosystem management (CEM), nature conservancy, US. IUCN, 2009, Gland, p 16 ISBN 978-2-8317-1215-4

Dempsey N, Burton M (2012) Defining place-keeping: the long-term management of public spaces. Urban For Urban Green 11:11-20

Descola P (2013) Beyond nature and culture. University of Chicago Press, Chicago

Díaz S et al (2018) Assessing nature's contributions to people. Science 359(6373):270-272. https://doi.org/10.1126/science.aap8826

Dobbs C, Martinez-Harms MJ, Kendal D (2017) Ecosystem services. Chapter in. In: Ferrini F, Konijnendijk van den Bosch C, Fini A (eds) Routledge Handbook of Urban Forestry. Routledge, Abingdon, pp 51-64

Driessen CPG (2017) "Hybridity." The International Encyclopaedia of Geography

Eksi M, Rowe DB, Wichman IS, Andresen JA (2017) Effect of substrate depth, vegetation type, and season on green roof thermal properties. Energ Buildings 145:174-187. https://doi.org/10.1016/j.enbuild. 2017.04.017

Elands BHM, Wiersum KF, Buijs AE, Vierikko K (2015) Policy interpretations and manifestation of biocultural diversity in urbanized Europe: conservation of lived biodiversity. Biodivers Conserv 24: $3347-3366$

Ernston H, Sörlin S (2013) Ecosystem services as technology of globalization: on articulating values in urban nature. Ecol Econ 86: 274-284

Escobedo FJ, Giannico V, Jim CY, Sanesi G, Lafortezza R (2018) Urban forests, ecosystem services, green infrastructure and nature-based solutions: nexus or evolving metaphors? Urban For Urban Green 2018:3-12. https://doi.org/10.1016/j.ufug.2018.02.011

European Commission (2004) Towards a Thematic Strategy on the Urban Environment. COM/2004/0060 final https://eur-lex.europa.eu/legalcontent/EN/TXT/?uri=celex:52004DC0060

European Commission (2013) Building a Green Infrastructure for Europe Luxembourg: Publications Office of the European Union 2013, pp 24. ISBN 978-92-79-33428-3. https://doi.org/10.2779/54125

European Commission (2015) Nature-Based Solutions \& Re-Naturing Cities. Final Report of the Horizon 2020 Expert group on 'naturebased solutions and re- Naturing cities'. Directorate-General for Research and Innovation-Climate Action, Environment, Resource Efficiency and Raw Materials. https://op.europa.eu/en/ publication-detail/-/publication/fb117980-d5aa-46df-8edcaf367cddc202/language-en

Faivre N, Fritz M, Freitas T, de Boissezon B, Vandewoestijne S (2017) Nature-based solutions in the EU: innovating with nature to address social, economic and environmental challenges. Environ Res 159: $509-518$

FAO (2017) The State of Food and Agriculture. Levering Food Systems for Inclusive Rural Transformation. Food and Agriculture Organization of the United Nations (FAO), Rome, 2017

Favoreu C, Carassus D, Maurel C (2015) Strategic management in the public sector: a rational, political or collaborative approach? Int Rev Adm Sci 82:435-453

Fischer LK, Honold J, Cvejić R et al (2018) Beyond green: broad support for biodiversity in multicultural European cities. Glob Environ Chang 49:35-45 
Forester JF (1999) The deliberative practitioner - encouraging participatory planning processes. The MIT Press, Cambridge, Massachusetts. London

Franklin A (2017) The more-than-human city. Sociol Rev 65(2):202-217

Frantzeskaki, N. (2019) Seven lessons for planning nature-based solutions in cities. Environ Sci Policy 93:101-111. https://doi.org/10. 1016/j.envsci.2018.12.033

Frantzeskaki N, Dumitru A, Anguelovski I et al (2016) Elucidating the changing roles of civil society in urban sustainability transitions. Curr Opin Environ Sustain 22:41-50

Frantzeskaki N, Borgström S, Gorissen L, Egermann M, Ehnert F (2017) Nature-based solutions accelerating urban sustainability transitions in cities: lessons from Dresden, Genk and Stockholm cities. In: Kabisch N, Korn H, Stadler J, Bonn A (eds) Nature-based solutions to climate change adaptation in urban areas. Theory and Practice of Urban Sustainability Transitions. Springer, Cham

Gobster PH, Nassauer JI, Daniel TC, Fry G (2007) The shared landscape: what does aesthetics have to do with ecology? Landsc Ecol 22(7): 959-972. https://doi.org/10.1007/s10980-007-9110-x

Grabosky J, Haffner E, Bassuk N (2009) Plant available moisture in stone-soil Media for use under Pavement while Allowing Urban Tree Root Growth. Arboricult Urban For 35(5):271-278

Hajer M, Nilsson M, Raworth K et al (2015) Beyond cockpit-ism: four insights to enhance the transformative potential of the sustainable development goals. Sustainability (Switzerland) 7:1651-1660

IPBES (2019) Global assessment report on biodiversity and ecosystem services of the intergovernmental science- policy platform on biodiversity and ecosystem services. In: Brondizio ES, Settele J, Díaz S, Ngo HT (eds). IPBES secretariat, Bonn, Germany

IPCC (2019) Climate change and land, an IPCC special report on climate change, desertification, land degradation, sustainable land management, food security, and greenhouse gas fluxes in terrestrial ecosystems. IPCC, Geneva. https://www.ipcc.ch/srccl-reportdownload-page/

Ives CD, David JA, von Henrik W, Christian D, Kathleen K, Joern F (2018) Reconnecting with nature for sustainability. Sustain Sci:1-9

Jansson M, Vogel N, Fors H, Randrup TB (2018) The governance of landscape management: new approaches to urban space development. Landsc Res 44:952-965. https://doi.org/10.1080/01426397. 2018.1536199

Kaplan S (1995) The restorative benefits of nature: toward an integrative framework. J Environ Psychol 15:169-182

Kloek ME, Buijs AE, Boersema JJ, Schouten MGC (2017) Beyond ethnic stereotypes - identities and outdoor recreation among immigrants and nonimmigrants in the Netherlands. Leis Sci 39:59-78

Kowarik I (2013) Cities and wilderness. A new perspective. International Journal of Wilderness 19(3):32-36 19

Kowarik I (2018) Urban wilderness: supply, demand, and access. Urban For Urban Green 29:336-347

Lakoff G, Johnson M (2003) Metaphors we live by. The University of Chicago Press Books ISBN: 9780226468013

Latour B (1993) We have never been modern. Harvester Wheatsheaf, New York

London.gov (2019) London National Park City. https://www.london.gov. uk/what-we-do/environment/parks-green-spaces-and-biodiversity/ london-national-park-city

Maas J, van Dillen SM, Verheij RA, Groenewegen PP (2009) Social contacts as a possible mechanism behind the relation between green space and health. Health Place 15:586-595
Mattijssen T, Buijs A, Elands B, Arts B (2018) The 'green' and 'self' in green self-governance-a study of 264 green space initiatives by citizens. J Environ Policy Plan 20:96-113

Meadows DH (1999) Leverage points : places to intervene in a system. Sustainability Institute, Hartland Four Corners

Nassauer JI (2011) Care and stewardship: from home to planet. Landsc Urban Plan 100:321-323

Nisbet EK, Zelenski JM, Murphy SA (2009) The nature relatedness scale: linking individuals' connection with nature to environmental concern and behavior. Environ Behav 41:715-740

Pauleit S, Hansen R, Lorance Rall E, Zölch T, Andersson E, Catarina Luz A, Szaraz L, Tosics I, Vierikko K (2017) Urban landscapes and green infrastructure. Oxford Research Encyclopedias. Environmental Science. Subject: Environment and Human Health, Management and Planning. https://doi.org/10.1093/acrefore/ 9780199389414.013.23

Pereira AG, Funtowicz S (2015) Science, Philosophy and Sustainability. The End of the Cartesian dream. Routledge, London

Ravallion M, Chen S, Sangraula P (2007) New evidence on the urbanization of global poverty. Popul Dev Rev 33(4):667-701

Roman LA, Scatena FN (2011) Street tree survival rates: meta-analysis of previous studies and application to a field survey in Philadelphia, PA, USA. Urban For Urban Green 10:269-274

Runhaar H, Runhaar P, Bouwmans M, Vink S, Buijs A, Kleijn D (2019) The power of argument. Int J Agric Sustain 17:231-242

Schröter M, van der Zanden EH, van Oudenhoven APE, Remme RP, Serna-Chavez HM, de Groot RS, Opdam P (2014) Ecosystem services as a contested concept: a synthesis of critique and counterarguments. Conserv Lett 6:514-523

Soga M, Gaston KJ (2016) Extinction of experience: the loss of humannature interactions. Front Ecol Environ 14:94-101

Sørensen E, Torfing J (2009) Making Governnace networks effective and democratic through Metagovernnace. Public Adm 87:234

TEEB (2010) The economics of ecosystems and biodiversity: mainstreaming the economics of nature: a synthesis of the approach, Conclusions and Recommendations of TEEB

Turnhout E, Waterton C, Neves K, Buizer M (2013) Rethinking biodiversity: from goods and services to "living with". Conserv Lett 6: 154-161

Unpopulation.org (2018) The speed of urbanization around the world. United Nations, Department of Economics and Social Affairs, Population Division. Population facts, no 2018/1, December 2018, 2 pp. (retrieved from ww.un.org, on May 20, 2019)

Whatmore S (2002) Hybrid geographies: natures, cultures, spaces. SAGE Publications, London

Whatmore S (2006) Materialist returns: practising cultural geography in and for a more-than-human world. Cult Geogr 13(4):600-609

Wild TC, Ogden S, Lerner DN (2008) An innovative partnership response to the management of urban river corridors - Sheffield's river stewardship company. 11th Int. Conf. On Urb. Drainage, IAHR/IWA, Edinburgh

Wild et al (2015) VALUE added project report. Final Report Policy Lessons and Recommendations. (https://www.researchgate.net/ publication/331167877. ISBN: 978-0-9930238-3-5

World Commission on Environment and Development (1987) Our Common Future. Oxford University Press, Oxford, p 27 ISBN 019282080X 